\title{
Detecting gene-gene interactions in prostate disease in African American men
}

\author{
R Renee Reams ${ }^{1 *}$, Krishna Rani Kalari ${ }^{2}$, Honghe Wang $^{3}$, Folakemi T Odedina ${ }^{4,5}$, Karam FA Soliman ${ }^{1}$, Clayton Yates ${ }^{3}$ \\ From The Science of Global Prostate Cancer Disparities in Black Men \\ Jacksonville, FL, USA. 27-29 August 2010
}

\begin{abstract}
Background: The most common male malignancy in the United States is prostate cancer; however its rate of occurrence varies significantly among ethnic groups. In a previous CDNA microarray study on CaP tumors from African American (AA) and Caucasian (CA) patients, we identified 97 candidate genes that exhibited opposite gene expression polarity with respect to race groups; genes up-regulated in AA were simultaneously down-regulated in CA.

Purpose: The purpose of this study was to narrow the 97 member gene list, to a smaller number of genes in order to focus studies on a limited number of genes/SNPs that might explain prostate cancer disparity in African Americans.

Methods: We performed genotype-phenotype, SNP and expression transcript levels correlations using HapMap Yoruba population with 85 of our 97 prostate candidate genes using SCAN database.

Results: Findings revealed an association of SNPs surrounding ABCD3 gene with basal gene expression of RanGAP1 is important in prostate tumors in AA. Hence, to confirm our results in clinical biospecimen, we monitored expression of $A B C D 3$ in a novel panel of African American and Caucasian prostate cancer paired cell lines. The LNCaP, C4-2B showed 2-fold increase; MDA-2PC-2B cell line, derived from AA, showed highest foldchange, 10-fold. The EGFR over expressing DU-145 WT cell line exhibited a 4-fold increase in expression relative to non transfected DU-145 prostate cell lines. Furthermore, Ingenuity Network analysis implicated our AA prostate candidate genes are involved in three network hubs, ERK, MapK and NFkB pathways.

Conclusions: Taken together, these findings are intriguing because other members of the ABC gene family, namely, $A B C C 3, A B C D 1$, and $A B C D 2$ have been shown to confer chemoresistance in certain cancer types. Equally important, is the fact that activation of the MapK/ERK pathway via EGFR stimulation is vital for increased transcription of numerous cancer related genes. It is especially noteworthy that overexpression of EGFR has been widely observed in AA prostate tumors. Collectively our findings lead us to think that a novel signaling cascade, through which increased aggressiveness and chemoresistance is achieved, may explain prostate cancer health disparity in AA males and the nature of aggressive CaP tumors in general.
\end{abstract}

\section{Introduction}

Prostate cancer $(\mathrm{CaP})$ is the second leading cause of cancer-related death among all men in the United States. However, incidence and mortality rates for this disease vary substantially among geographic areas and ethnic groups. Most notably African American men (AA) in the United States have the highest risk (19\%) of developing

\footnotetext{
* Correspondence: renee.reams@famu.edu

'College of Pharmacy and Pharmaceutical Sciences, Florida A\&M University,

Tallahassee, Florida, USA

Full list of author information is available at the end of the article
}

prostate cancer, and due to the development of more aggressive disease, they have more than twice the mortality rate observed for other racial and ethnic groups [1]. The explanation for these differences is still unknown; however proposed explanations include genetic factors, dietary factors, behavioral factors, biological tumor aggressiveness, socio-economic factors and gene-environment interaction [2-35]. While AA race/ethnicity is one of the three primary non-modifiable risk factors confirmed for $\mathrm{CaP}$, there are only a few published cDNA microarray studies [36-38] that have focused on gene expression differences in AA

\section{() Biomed Central}


tumors compared to CA in an attempt to understand prostate cancer health disparity. Previously we identified 97 genes differentially expressed in AA prostate tumors. To narrow down this number of genes, we utilized advance bioinformatics methods. In the present study we performed genotype-phenotype or SNP and expression transcript level correlations of HapMap lymphoblastoid cell lines from Yoruba population to the 97 prostate candidate genes in AA, in an attempt to ferret out genetic variants associated with AA population. In addition, we used Ingenuity pathway analysis to calculate the probability of finding our set of candidate genes within a given pathway(s) to establish probable signal transduction mechanisms.

\section{Methods}

\section{Microarray prostate candidate gene list for AA tumors}

The gene list used in this study was obtained from our previously published cDNA microarray study [36].

\section{SCAN database analysis to look for gene-gene interactions}

SCAN is a large-scale database of genetics and genomics data associated to a web-interface and a set of methods and algorithms that can be used for mining the data in it (http://www.scandb.org/newinterface/about.html). Information on the relationship between SNPs and expression transcript levels (eQTLs) that is served by SCAN comes from a series of publications describing studies characterizing eQTLs in lymphoblastoid cell lines from HapMaP Caucasian (CEU) and Yoruba (YRI) samples for which transcript levels have been assayed using the Affymetrix Human Exon 1.0 ST Array [39-44].

The SCAN database contains two categories of SNP annotations: (1) Physical-based annotation or SNPs categorized according to their position relative to genes (intronic, antigenic, etc.) and according to linkage disequilibrium (LD) patterns (an intergenic SNP can be annotated to a gene if it is in LD with variation in the gene). (2) Functional annotation where SNPs are classified according to their effects on expression levels, i.e. whether they are eQTLs for that gene. Information on physical, functional and LD annotation served on the SCAN database comes directly from public resources, including HapMap (release 23a), NCBI (dbSNP 129), or is information created by using data downloaded from these public resources. In SCAN database, genotype data for the YRI samples was obtained from HapMap project (http://www.hapmap.org). Genotype and gene annotations were obtained from NCBI, dbSNP 129.

We uploaded appropriate gene identifiers for our prostate candidate genes and queried for SNPs that are significantly associated with expression of prostate candidate genes in Yoruba (YRI) population in lymphoblastoid cell lines. SCAN genetic and genomic data for the Yoruba
Population in Ibaden, Nigeria, Africa was used because of close ancestral ties of Nigerians to African Americans. The SCAN analysis output reports a list of SNPs in gene (s) that predict expression quantitative trait loci found in mRNA profiles from YRI with p-values less than 0.0001 .

\section{Hugo gene symbols}

To enter a list of genes into SCAN, it is first necessary to use the HUGO (Human Genome Organization) gene symbol - the unique gene name and symbol given to each human gene by The HUGO Gene Nomenclature Committee (HGNC). From our 97 gene list, we were able to obtain HUGO gene symbols for 85 of the 97 genes (hereafter referred to as 85/97).

\section{Ingenuity pathway analysis}

Ingenuity software (http://www.ingenuity.com/) was used for pathway analysis. Ingenuity software calculates p-value for the probability of finding a set of genes within a given pathway. Fisher's exact test was used to calculate the p-values associated with finding 536 prostate genes obtained during this study (which includes 85/97 candidate genes, from previous differential expression study [36] and 451 candidate genes that are corresponding to Cis- regulatory SNPs, that are significantly associated with the 85 candidate genes) within a annotated network from Ingenuity Knowledge Base.

\section{RT-PCR validation in novel panel of prostate cancer lines} RT-PCR assay was done using a 7500 FAST Real-Time ABI System.

Briefly, total RNA from each cultured prostate cell line was extracted, separately, with RNAzol B (Tel-Test Inc., Friedswood, Tx) according to the manufacturer's protocol and quantified with Nucleic Acid Quantitation Kit (NBI, Plymouth, MN). Total RNA (1 ug) was reverse transcribed into cDNA with $\mathrm{RT}^{2}$ First strand Kit (SABiosciences/A Qiagen Company)) and 1.10 of the reverse-transcribed product from each sample was used for PCR to amplify ABCD3 gene, using a $\mathrm{RT}^{2}$ qPCR Primer Assay for Human ABCD3 (SABiosciences/A Qiagen Company) The expression of GAPDH was used as an internal control/housekeeping gene. Experimental conditions for the ABCD3 gene was optimized to analyze the amplified product in the linear range of amplification by adjusting amplification cycles for each set of primers. The expected band size (bp) size of the PCR product was 83 , as described by vendor (SABiosciences).

\section{Novel prostate cancer cell lines: description}

Non-malignant (RC-77N/E) and malignant (RC-77T/E) prostate cells were derived from an African American prostate cancer patient and both are androgen sensitive [45]. RC-77N/E cells were isolated from pathological 
normal cells, while RC-77T/E were derived from stage T3 tumor. Both cell lines are cultured in Keratinocyte Serum-Free Medium (KGM) Life Technologies, Gaithersburg, Md., USA), supplemented with bovine pituitary extract (BPE), recombinant epidermal growth factor (rEGF), 1\% (v/v) penicillin-streptomycin-neomycin (PSN) antibiotic mixtures and 1\% (v/v) amphotericin B (KGM) (Life Technologies, Gaithersburg, MD, USA). MDA-2PC-2B, also derived from an African American patient are androgen dependent, metastatic and are cultured in F12 K medium. DU-145, a cell line originally derived from a brain metastasis of a human prostate adenocarcinoma [46] retains the androgen independence of the original tumor and does not express a functional AR [47]. This cell line has both LHRH-R and epidermal growth factor receptors (EGFR) and produces the EGFR ligands, transforming growth factor $\alpha$ (TGF- $\alpha$ ) and EGF $[48,49]$. Utilizing established protocols, DU-145 cells were transfected by retroviral-containing EGFR constructs [50]. The wild-type (WT) EGFR construct is a full-length cDNA derived from a placental cDNA library. Cells expressing WT EGFR at levels that escape downregulation demonstrate enhanced invasiveness in vitro [51]. LNCaP cells were derived from a lymph node metastasis [52]. The Caucasian LNCaP, C42-B prostate cancer cell lines were maintained in T-medium as previously described.

\section{Results}

\section{Origin of the 97 prostate candidate genes}

To detect for gene-gene interactions in AA prostate tumors in African American males, we used a cDNA microarray gene list obtained from a pilot project cDNA microarray comparison study of prostate tumor gene expression in AA and CA [36]. To obtain differentially expressed gene or the gene list, we used four snap frozen tumors and four snap frozen non-tumor matched controls, each, from AA and CA . All tumors had a Gleason score of six. Gene expression profiles were measured for each of the micro dissected $\mathrm{CaP}$ tumor samples using Affymetrix U133A human arrays as described in [36]. Each of the 8 prostate tumors and 8 matched controls underwent single hybridization and was arrayed individually (i.e. samples were not pooled). Data from the micro array CEL files were uploaded to R-Bioconductor for analysis [53]. We paired normal AA tissue to tumor AA and paired normal $\mathrm{CA}$ to tumor CA to generate for case paired $\mathrm{t}$-tests for each race group; gene lists of differentially expressed genes in AA Tumor vs. AA controls and of CA Tumor vs. CA controls were generated. We looked for differentially expressed genes that met the filtering criteria of a 4.0-fold change and a $\mathrm{p}<0.0001$. Neither the comparison of AA tumor to AA controls nor the comparison CA tumors to CA controls yielded genes that met both parts of our filtering criteria. However, when we looked at the ratio of CA tumor/CA normal to AA tumor/AA normal (casematched ratios-race group tests for specific expression trends) we found 97 statistically significant, differentially expressed genes with 4-fold or greater fold change and $\mathrm{p}<0.0001$. It was necessary to ratio the ratios to control for the high degree of genetic variation in AA tumor and AA non-tumor samples.

\section{Scan database SNP and expression transcript level association results}

After uploading our 85/97 prostate candidate genes with appropriate HUGO gene symbols and querying for SNPs in our 85/97 significantly associated with SNPs in the HapMap Yoruba (YRI) population; approximately, 26527 genotype-phenotype associations were obtained with a $\mathrm{p}$-value $<10^{-3}$, of which $17542 / 26527$ associations had a $\mathrm{p}$-value $<10^{-4}$ ( data not shown)

SNPs and expression transcript levels (eQTL) associations results identified two gene-gene associations. Association results in lymphoblastoid cell lines showed that expression of RanGAP1 gene which is a key regulator of the RAN GTP/GDP cycle, located on chromosome 22, may be involved with several SNPs in ABCD3 gene which is ATP-Binding cassette, subfamily member that is located on chromosome 1 (Shown as encircled dots on far left in Figure 1). In addition, expression of STXBP2 gene which is a syntaxin-binding protein that is located on chromosome 19 may be involved with a region on chromosome 12. The chromosome 12 region consists of transmembrane and tetratricopeptide repeat containing 2 (TMTC2) gene that is approximately $400 \mathrm{~kb}$ away from the region where STXBP2 gene is associated (shown as encircled dots on far right of Figure 1). Genome-wide results also showed that there were 1167 cis interactions (where expression gene and SNP are located on the same chromosome) out of 26527 associations with a p-value $<10^{-3}$. Most of the cis-regulatory associations were found in protein coding regions.

CaP candidate genes found in ERK, MapK, NFKB pathways Pathway analysis was performed in an attempt to define biological relationships among candidate genes identified during our study using the genes that are involved with the downstream effects of SNPs along with the 85/97 candidate prostate cancer genes as described in methods. Ingenuity Pathway Analysis (IPA) was used to perform the pathway analysis. This software consists of a curated database and several analysis tools to determine the probability of finding a set of genes within annotated pathway or network annotation. Results showed a high probability for finding our candidate genes in three network hubs centered on ERK, MAPK and NFkB pathways (Shown in Figures 2, 3 and 4, respectively). These 


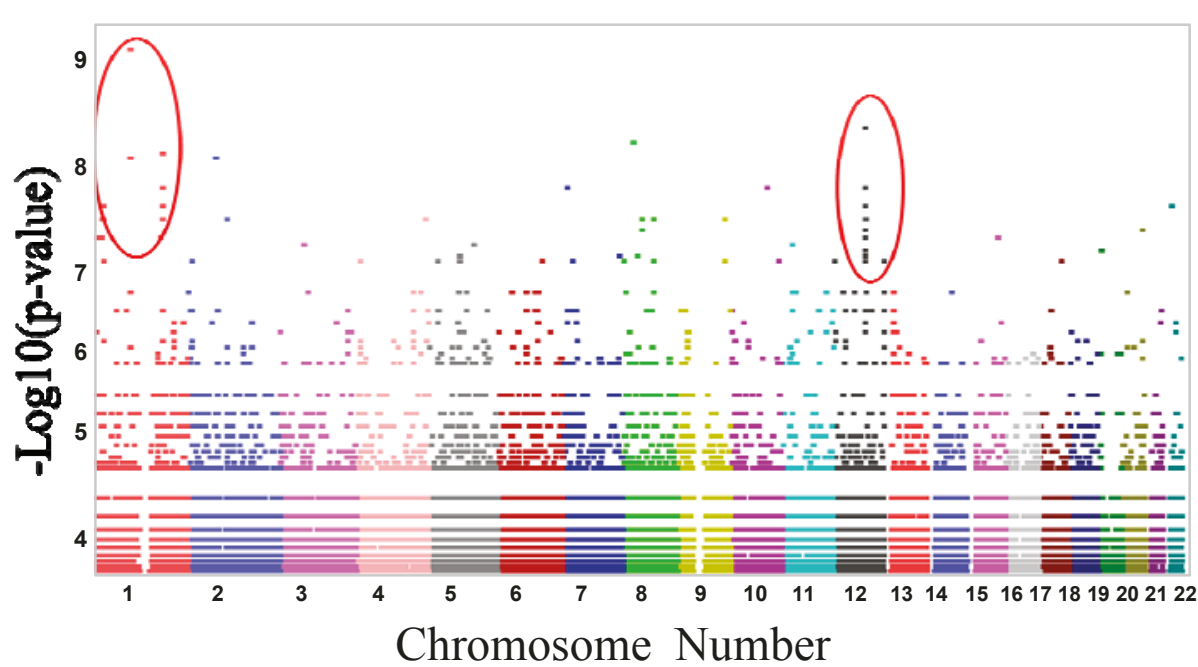

Figure 1 GWAS Plot of Gene-Gene Associations illustrates p-values (shown on $y$-axis) of SNP for gene variants found on chromosomes 1-22(xaxis). The $x$-axis shows Chromosomes 1 thru 22. Each dot represents gene variants or SNPs. In the circled dots to the extreme left positioned above Chromosome 1 (x-axis), the dot with the highest $p$-value represents an ABCD3 gene variant with a defined rs\# that is strongly interacting with RANGAP1 to influence CaP tumors in African American. All of the dots in the circle reveal an association of SNPs surrounding ABCD3 gene with basal gene expression of RanGAP1. This variation in gene expression RanGAP1 might be influenced by the SNPs in ABCD3 Similarly in the circled points to the far right, positioned above chromosome 12 ( $x$-axis), the dot with the highest p-value represents the TMTC2 gene variant with a defined rs\#, that strongly interacts with STXBP2. All the dots in the circle represent an association of SNPs surrounding TMTC2 gene with basal gene expression of STXBP2.

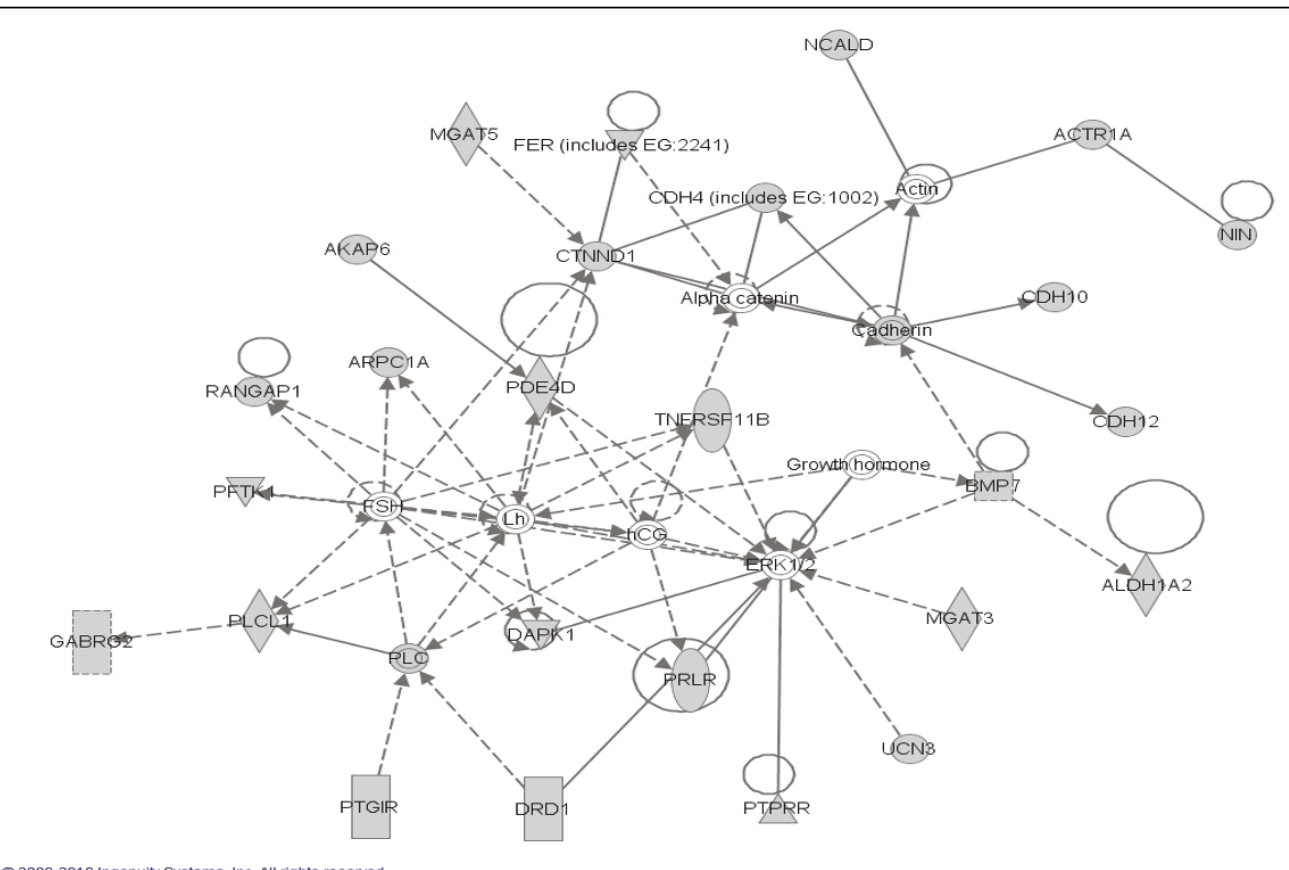

Figure 2 Ingenuity Pathway Analysis identified ERK as the Top network signaling Hub where the shaded shapes indicate the candidate genes from the present study. RANGAP1 is found in the ERK pathway. Dotted line indicates an indirect cellular interaction and solid lines indicate a physical interaction between genes. Genes are identified with their HUGO symbol. Dotted line indicates an indirect cellular interaction and solid lines indicate a physical interaction (acts on or inhibits) between genes. Different shapes (diamond, circle or rectangles) of the nodes represent functional classification of the genes. 


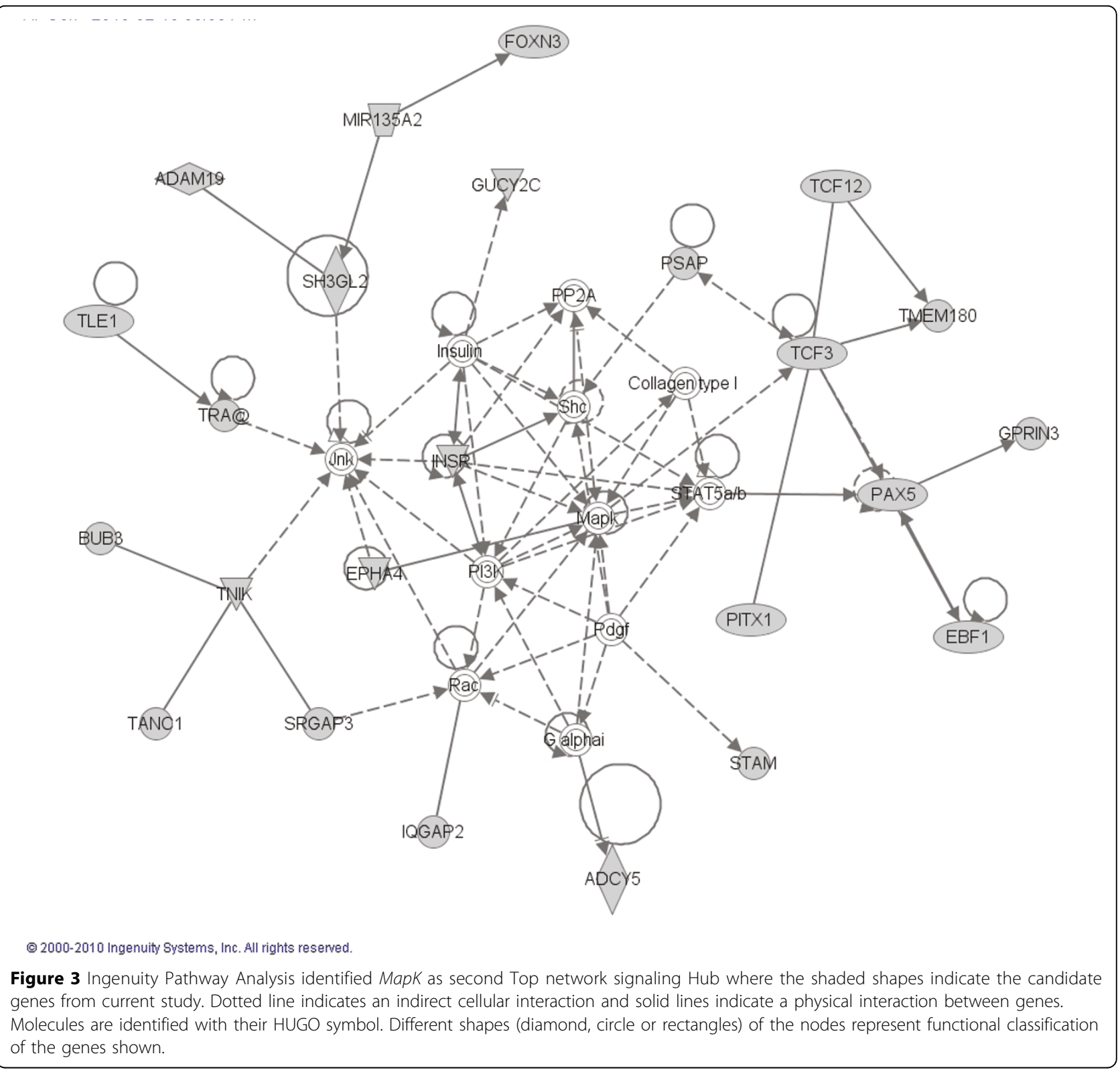

"top" three networks with p values of $<0.05$ based on Fisher's exact test were associated with genetic disorder, cellular development, cell death and cell signaling. Direct interactions between the genes in the network pathways are indicated by solid lines and indirect relationships are indicated by dashed lines. The shaded genes represent our 536 candidate genes identified in our association study as described in method section ( 85 candidate genes +451 cis-regulatory genes that are associated with the 85 candidate genes). Diamond shapes represent enzymes, oval represent transcription regulators. Squares: cytokines and triangles: kinases. (For full explanation of shapes and the functional classification they represent go to http://www.springerimages.
com/Images/LifeSciences/1-10.1007_s12014-0109053-0-2),

\section{$A B C D 3$ gene highly expressed in aa metastatic prostate cancer lines}

Our association study of 85 candidate genes with genome-wide SNPs in HapMap YRI lymphoblastoid cell lines has revealed an association of SNPs surrounding $\mathrm{ABCD} 3$ gene with basal gene expression of RanGAP1 using data obtained from SCAN database (Figure 1). This variation in expression levels of RanGAP1 might be influenced by the SNPs in ABCD3. To confirm our results obtained during the association study, we tested ABCD3 expression in clinically relevant cell lines. Verification of 


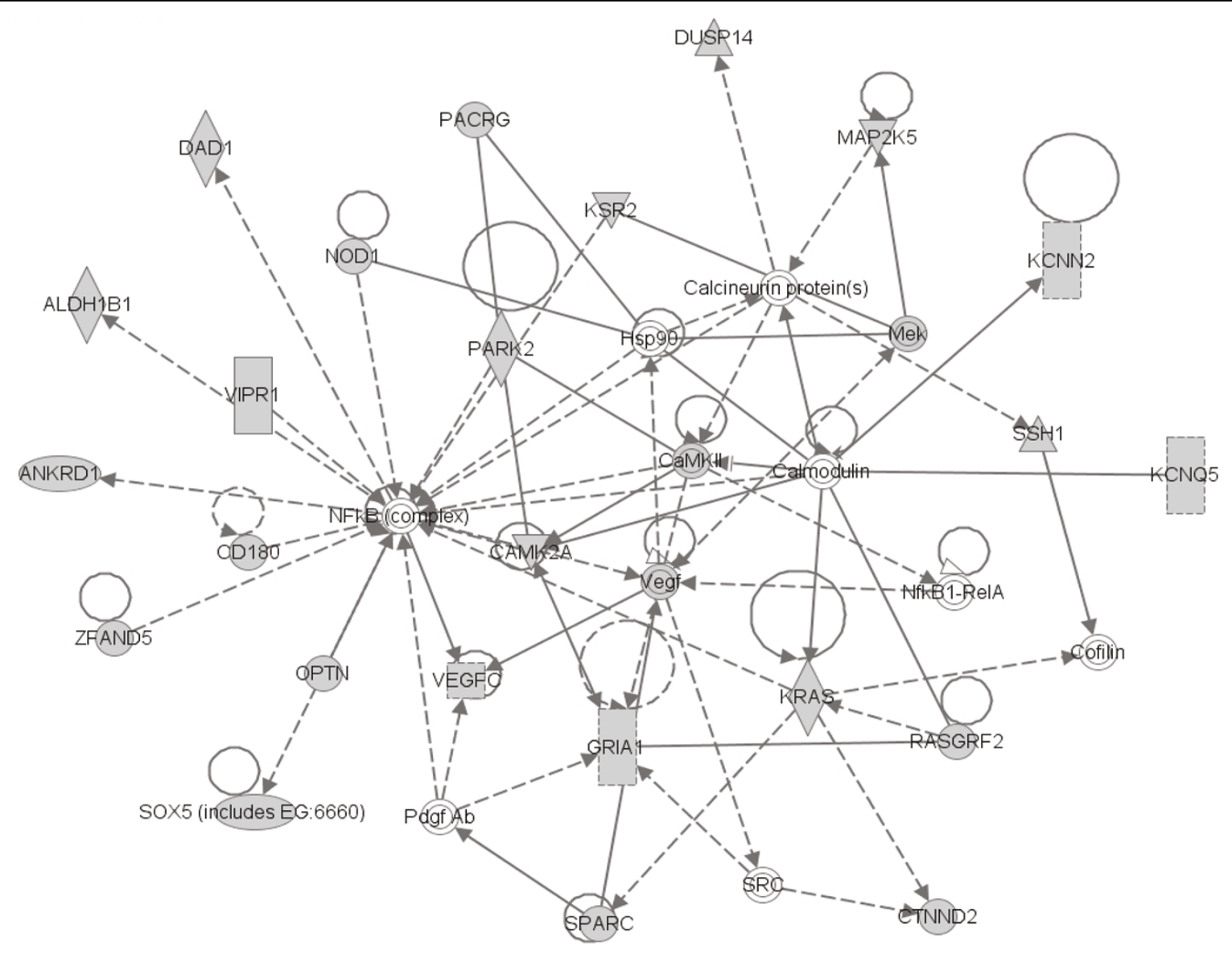

@ 2000-2010 Ingenuity Systems, Inc. All rights reserved.

Figure 4 Ingenuity Pathway Analysis identified NFKB as the Top Network signaling Hub where the shaded shapes indicate the candidate genes from the present study. Dotted line indicates an indirect cellular interaction and solid lines indicate a physical interaction (.I.e. binding) between genes. Molecules are identified with their HUGO symbol. Different shapes (diamond, circle or rectangles) of the nodes represent functional classification of the genes shown.

$\mathrm{ABCD} 3$ in novel AA/CA prostate cancer cell lines revealed an increase in expression with increased metastasis across a novel panel of African American and Caucasian prostate cancer paired cell lines (Figure 5). The malignant RC-77T/E cells isolated from AA showed 2fold increased expression compared to non-malignant RC-77N/E matched pair (Figure 5). The metastatic, androgen dependent MDA-2PC-2B cell line derived from AA ) exhibited a 10-fold ABCD3 expression (Figure 5). Previously we have demonstrated that DU-145 WT (EGFR overexpressing) cells exhibit increased invasiveness and metastasis both in vitro and in vivo [49]. Therefore, we examined ABCD3 gene expression in the DU-145 WT cell and in non-transfected DU-145 cells. DU-145 WT cells showed a 4-fold increase in expression relative to DU-145 prostate cell lines (Figure 5). A similar pattern of expression was observed in the androgen independent metastatic C4-2B cells derived from Caucasian androgen dependent $\mathrm{LNCaP}$ cells, thus providing firm evidence of increased $\mathrm{ABCD} 3$ gene expression with increased prostate cancer progression in AA tumors (Figure 5).

\section{Discussion/conclusion}

To address the underlying genetic cause of prostate cancer burden in African Americans, we previously obtained a cohort of normal tumor paired samples from African American and Caucasian men, and looked for differential gene expression within each group. Utilizing a strict filtering criteria, we observed over 97 differentially expressed genes in our African American vs. Caucasian sample set [36]. To further narrow the list to genes of utmost importance in prostate disease onset, we used a genome-wide association approach that allowed us to rapidly scan for SNPs in the genome of healthy Yorubai population (Yorubai from Ibaden, Nigeria) that might possibly be associated 


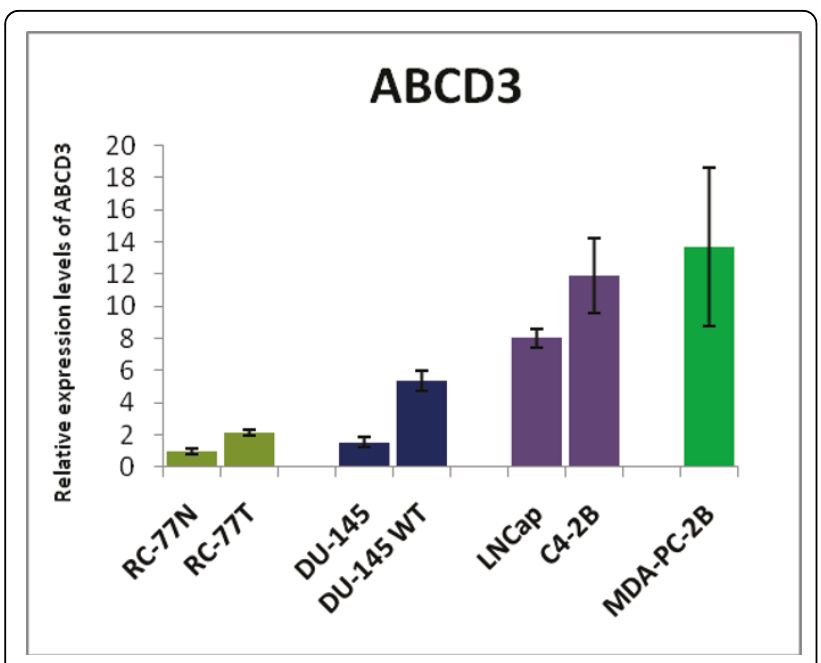

Figure 5 Expression of $A B C D 3$ in panel of paired prostate cancer cell lines. (A) qRT-PCR of non-malignant African American RC-77N/E was compared to malignant RC-77T/E cells, DU-145 was compared to DU-145 WT (EGFR overexpressing), LnCaP was compared to C4$2 \mathrm{~B}$, and all samples were compared to African American MDA-PC-2b cells. Results shown is representative of experiments performed in triplicate.

with our 85/97 prostate candidate genes. We utilized the HapMap database of YBI, Nigerian lymphoblastoid cell lines, since there are a limited number of SNP databases containing African American patients. Most importantly the Yorubai population rather than the Caucasian (CEU) population was utilized because the close ancestral ties [54] between West African Africans and African Americans would increase our chances of finding similar genetic variants associated with prostate disease in men of African descent (Nigerians and African Americans). Approximately 536 genes were identified in our association study as described in methods section (85 candidate genes +451 cis-regulatory genes) that are associated with the $85 / 97$ candidate genes. Herein we report that a significant number of direct gene-gene interactions were found, however the most significant interactions were observed on chromosome 1 and chromosome 12. Given the importance of these chromosomes in prostate disease, it was appropriate to investigate ABCD3 gene involvement in African American prostate cancer. Our analysis of gene-gene interactions on chromosome 1 and 12 revealed that ABCD3/RanGAP1 and STXBP and TMTC2 gene showed the strongest associations. Of these the ABCD3/RanGAP1 genes were predicted to have the most significant interactions. As such neither ABCD3 or RanGAP1 expression has been implicated in prostate cancer, therefore we chose to focus on ABCD3. The ATP-binding cassette genes consist of various subfamilies, are typically expressed in both normal and cancer cells. Their functions have been implicated in acquired Multidrug Resistance, MDR, in cancer cell lines.
For example, recent reports have shown that MCF-7/ AdVp3000 cells that were derived by selection for growth in the presence of doxorubicin, exhibit a 459-fold overexpression of ABCC3 relative to the parental cell line [55]. A similar situation in prostate cancer cell lines has been observed as MDR1/Pgp/ABCB1 and multidrug resistanceassociated protein-1(MRP1/ABCC1), with the half $A B C$ transporter, breast cancer resistance protein BCRP/ ABCG2, is able to selectively isolate the putative prostate stem cells from the prostate tissue microenvironment through constitutive efflux of androgen and protects the putative tumor stem cells from androgen deprivation, hypoxia, or adjuvant chemotherapy [56]. These findings are supported by unpublished data, from Yates laboratory, that suggest that fluorescence-activated cell sorting, FACS isolation of the (SP) cells, selective for functional ABC transporter pumps, have higher in vivo tumorigenicity compared to other cell surface markers (unpublished data). Thus, it is possible that ABCD3 could possibly contribute to aggressive prostate cancer.

Multiple ABC family genes have been implicated to play a role in chemoresistance and progression of prostate and breast cancer, however given the large number of family subtypes only a few have been associated with prostate cancer progression to aggressive disease. Since ABCD3 gene expression has not been identified previously in prostate cancer, we verified this in commonly utilized prostate cancer cell lines, as well as in a normal and primary tumor cell line pair derived from an African American prostate cancer patient $[45,57]$. As in prostate patient samples, $\mathrm{ABCD} 3$ was consistently overexpressed in the RC-77N/E/ RC-77T/E, LNCaP/C4-2B models, with MDA-PC-2B cells exhibiting the highest expression (10-fold). This data is consistent with the expression of other members of the $\mathrm{ABC}$ gene family that have been implicated in prostate cancer, and serves as proof-of-principle evidence that ABCD3 overexpression is indeed correlated with prostate cancer progression. That MDA-2PC-2B cells exhibited the highest expression levels, further implicates a role for ABCD3 in African American prostate cancers.

To further substantiate the link of ABCD3 with other cell signaling molecules that contribute to prostate cancer, we utilized an indirect in silico ingenuity pathway analysis. ABCD3, showed a high probability of being found within three growth factor initiated network hubs involving ERK, MAPK and NFkB proteins. The ERK MAPK has been implicated in a number of pathophysiological events including androgen receptor signaling [58] and the epithelial-to-mesenchymal (EMT) [59] that occurs as cancer cells acquire the property to metastasize. That we observed a 4 fold increase in ABCD3 expression in an EGFR overexpressing DU-145 WT cell line compared to non-transfected DU-145 cells, highlights a putative novel regulator of ABCD3. EGFR is overexpressed in 
African American Prostate patients [60] and a robust activator of MAPK ERK in normal and cancer cell [61]. Furthermore overexpression is sufficient to increase proliferation, invasion related EMT, and metastasis $[49,62,63]$. Thus, it appears that ABDC3 is a novel prostate cancer associated gene, that could, in part, be regulated by EGFR signaling.

Although further studies to investigate the $\mathrm{ABCD} 3 /$ RanGAP1 relationship need to be conducted, our results clearly illustrate the utility of high density SNP analysis, in conjunction with appropriate cell lines that represent the clinical conditions, to identify regulatory genes in prostate cancer. Although a more in-depth analysis of the exact role of $\mathrm{ABCD} 3$ in such events as cell proliferation, and chemoresistance is warranted and are underway. The results of this study provide a rationale for use of DU-145/ DU-145WT and MDA-PC-2B as culture models to study molecular mechanisms associated with the health disparity in African American prostate cancer patients.

\section{Limitation of study}

The 97 member candidate gene list was derived from a limited number of prostate tumor samples and matched control from AA and CA. Nonetheless, approximately, 26527 genotype-phenotype associations were obtained with a p-value $<10^{-3}$, of which $17542 / 26527$ associations has a p-value $<10^{-4}$. The associations with the highest Pvalues showed two distinct association; one of which has led us to think that the ABC gene family plays an important role in prostate cancer aggressiveness and chemoresistance.

\section{Acknowledgements \\ We acknowledge DoD Grant \# W81XWH-04-1-03-26 and NIH/NCRR/RCMI Grant \# SG12RR0020-26 to R.R.R; Mayo Clinic Dept of Medical Informatics for support services to K.R.K; Grant\# G12RR03059-21A1 to C.Y; RCMI Cancer Cluster for provided networking opportunities among its investigators ( R.R.R. and C. Y.) Special thanks to Karunya Kandimalla for introducing R.R.R. to K.R.K. This article has been published as part of Infectious Agents and Cancer Volume 6 Supplement 2, 2011: Proceedings of the First Biennial Conference on the Science of Global Prostate Cancer Disparities in Black Men. The full contents of the supplement are available online at http://www. infectagentscancer.com/supplements/6/S2.}

\section{Author details}

${ }^{1}$ College of Pharmacy and Pharmaceutical Sciences, Florida A\&M University, Tallahassee, Florida, USA. ${ }^{2}$ Department of Medical Informatics, Mayo Clinic College of Medicine, Rochester, MN, USA. ${ }^{3}$ Dept of Biology and Center for Cancer Research, Tuskegee University, Tuskegee, Alabama, USA. ${ }^{4}$ College of Pharmacy, University of Florida, Gainesville, Florida, USA. ${ }^{5}$ Prostate Disease Center, Department of Urology, University of Florida, Gainesville, Florida, USA.

\section{Authors' contributions}

All authors read and approved the final manuscript.

RRR identified the 97 prostate candidate genes in a previous study; RRR was responsible for the GWAS study design, manuscript preparation, editing \& critical revisions of the manuscript. KRK conducted the GWAS study and ingenuity pathway analysis studies and contributed to manuscript preparation. HW conducted RT-PCR experiments using novel panel of prostate cell lines contributed by CY. CY established novel panel of prostate cell lines; contributed their use for this study (in his laboratory) and provided critical revisions and pertinent scientific discussions of his published and unpublished data that linked ABCD3 gene expression in metastatic cell lines to being regulated in part by EGFR. FTO. and KFAS participated in scientific discussions, proofing of the manuscript and brought together $C Y$ and RRR as collaborators.

\section{Competing interests}

The authors do not have any competing interests to declare.

Published: 23 September 2011

\section{References}

1. American Cancer Society Facts and Figures (2008). Atlanta: American Cancer Society.

2. Powell IJ: Keynote address: prostate cancer among African-American men-from the bench to the community. Prostate cancer and AfricanAmerican men. Oncology (Williston Park) 1997, 11(5):599-605, discussion 606-15 passim. Review.PMID: 9159788.

3. Powell IJ: Prostate cancer in the African American: is this a different disease? Semin Urol Oncol 1998, 16(4):221-6, Review.PMID: 9858329.

4. Giovannucci E, Platz EA, Stampfer MJ, Chan A, Krithivas K, Kawachi I, et al: The CAG repeat within the androgen receptor gene and benign prostatic hyperplasia. Urology 1999, 53:121-5, doi:10.1016/S0090-4295(98)00468-3.

5. Caskey CT, Pizzuti A, Fu YH, Fenwick RG Jr, Nelson DL: Triplet repeat mutations in human disease. Science 1992, 256(5058):784-9, doi:10.1126/ science.1589758.

6. Platz EA, Rimm EB, Willett WC, Kantoff PW, Giovannucci E: Racial variations in prostate cancer incidence and in hormonal system markers among male health professionals. J Nat/ Cancer Inst 2000, 92(24):2009-17, doi:10.1093/jnci/92.24.2009.

7. Smith GE, DeHaven MJ, Grundig JP, Wilson GR: African-American males and prostate cancer: assessing knowledge levels in the community. $J$ Natl Med Assoc 1997, 89(6):387-91.

8. Barber KR, Shaw R, Folts M, Taylor DK, Ryan A, Hughes M, et al: Differences between African-American and Caucasian men participating in a community-based prostate cancer screening program. J Community Health 1998, 23(6):441-51, doi:10.1023/A:1018758124614.

9. Abbott RR, Taylor DK, Barber K: A comparison of prostate knowledge of African-American and Caucasian men: Changes from prescreening baseline to post-intervention. Cancer J Sci Am 1998, 4(3):175-7.

10. Steele CB, Miller DS, Maylahn C, Uhler RJ, Baker CT: Knowledge, attitudes, and screening practices among older men regarding prostate cancer. Am J Public Health 2000, 90(10):1595-600.

11. Agho AO, Lewis MA: Correlates of actual and perceived knowledge of prostate cancer among African Americans. Cancer Nurs 2001, 24(3):165-71, doi:10.1097/00002820-200106000-00001.

12. Ashford AR, Albert SM, Hoke G, Cushman LF, Miller DS, Bassett M: Prostate carcinoma knowledge, attitudes, and screening behavior among AfricanAmerican men in Central Harlem, New York City. Cancer 2001, 91(1):164-72, doi:10.1002/1097-0142(20010101)91:13.0.CO;2-A.

13. Magnus M: Prostate cancer knowledge among multiethnic black men. J Natl Med Assoc 2004, 96(5):650-6.

14. Richardson JT, Webster JD, Fields NJ: Uncovering myths and transforming realities among low-SES African-American men: Implications for reducing prostate cancer disparities. J Natl Med Assoc 2004, 96(10):1295-302

15. Woods VD, Montgomery SB, Belliard JC, Ramirez-Johnson J, Wilson CM: Culture, black men, and prostate cancer: What is reality? Cancer Control 2004, 11(6):388-96

16. Forrester-Anderson IT: Prostate cancer screening perceptions, knowledge, and behaviors among African American men: Focus group findings. J Health Care Poor Underserved 2005, 16(4, Suppl A):22-30, doi:10.1353/ hpu.2005.0122.

17. Jones AR, Shipp M, Thompson CJ, Davis MK: Prostate cancer knowledge and beliefs among black and white older men in rural and urban counties. J Cancer Educ 2005, 20:96-102, doi:10.1207/s15430154jce2002_10.

18. Ross LE, Uhler RJ, Williams KN: Awareness and use of prostate-specific antigen test among African-American men. J Natl Med Assoc 2005, 97(7):963-71. 
19. Pruthi RS, Tornehl C, Gaston K, Lee K, Moore D, Carson CC, et al: Impact of race, age, income, and residence on prostate cancer knowledge, screening behavior, and health maintenance in siblings of patients with prostate cancer. Eur Urol 2006, 50(1):64-9, doi:10.1016/j.eururo.2005.09.024.

20. McWhorter WB, Schatzkin AG, Horm JW, Brown CC: Contribution of socioeconomic status to Black/White differences in cancer incidence. Cancer 1989, 63:982-7, doi:10.1002/1097-0142(19890301)63:53.0.CO;2-I.

21. Baguet CR, Horm JW, Gibbs T, Greewald P: Socioeconomic factors and cancer incidence among Blacks and Whites. J Natl Cancer Inst 1991, 83:551-7, doi:10.1093/jnci/83.8.551

22. Robbins AS, Whittemore AS, Van Den Eeden SK: Race, prostate cancer survival, and membership in a large health maintenance organization. J Natl Cancer Inst 1989, 90(13):986-90, doi:10.1093/jnci/90.13.986.

23. Brawn PN, Johnson EH, Kuhl DL, Riggs MW, Speights VO, Johnson CFIII, et al: Stage at presentation and survival of white and black patients with prostate carcinoma. Cancer 1993, 71(8):2569-73, doi:10.1002/1097-0142 (19930415)71:83.0.CO;2-R.

24. Ndubuisi SC, Kofie VY, Andoh JY, Schwartz EM: Black-white differences in the stage at presentation of prostate cancer in the District of Columbia. Urology 1995, 46(1):71-7, doi:10.1016/50090-4295(99)80162-9.

25. Freedland SJ, Amling CL, Dorey F, Kane CJ, Presti JC, Terris MK, et al: Race as an outcome predictor following radical prostatectomy: Results from the Shared Equal Access Regional Cancer Hospital (SEARCH) Database. Urology 2002, 60:670-4, doi:10.1016/S0090-4295(02)01847-2.

26. Polednak AP, Flannery JT: Black versus white racial differences in clinical stage at diagnosis and treatment of prostatic cancer in Connecticut. Cancer 1992, 70:2152-8, doi:10.1002/1097-0142(19921015)70:83.0.CO;2-\#.

27. Moul JW, Sesterhenn IA, Connelly RR, Douglas T, Srivastava S, Mostofi FK, et al: Prostate-specific antigen values at the time of prostate cancer diagnosis in African American men. J Am Med Assoc 1995, 274:1277-81.

28. Horner RD: Racial variation in cancer care: A case study of prostate cancer. Cancer Treat Res 1998, 97:99-114, doi:10.1007/978-0-585-30498-4_8

29. Brawley OW, Knopf K, Thompson I: The epidemiology of prostate cancer part II: The risk factors. Semin Urol Oncol 1998, 16:193-201.

30. Fowler JE Jr, Bigler S, Bowman G, Kilambi N: Race and cause specific survival with prostate cancer: Influence of clinical stage, Gleason score, age and treatment. J Urol 2000, 163(1):137-42, doi:10.1016/50022-5347(05) 67989-X.

31. Whittemore AS, Kolonel LN, Wu AH, John EM, Gallagher RP, Howe GR, et al: Prostate cancer in relation to diet, physical activity, and body size in blacks, whites, and Asians in the United States and Canada. J Natl Cancer Inst 1995, 87(9):652-61, doi:10.1093/jnci/87.9.652.

32. Freedland SJ, Isaacs WB: Explaining racial differences in prostate cancer in the United States: Sociology or biology? Prostate 2005, 62:243-52, doi:10.1002/pros.20052.

33. Guo Y, Sigman DB, Borkowski A, Kyprianou N: Racial differences in prostate cancer growth: Apoptosis and cell proliferation in Caucasian and African-American patients. Prostate 2000, 42:130-6, doi:10.1002/(SICI) 1097-0045(20000201)42:23.0.CO;2-3.

34. Ross R, Bernstein L, Judd H, Hanisch R, Pike M, Henderson B: Serum testosterone levels in healthy young black and white men. J Natl Cancer Inst 1986, 76:45-8.

35. Ross R, Bernstein L, Lobo RA, Shimizu H, Stanczyk FZ, Pike MC, et al: 5alpha-reductase activity and risk of prostate cancer among Japanese and US White and Black males. Lancet 1999, 339:887-9, doi:10.1016/01406736(92)90927-U.

36. Reams RR, Agrawal D, Davis M, Yoder S, Odedina F, Kumar N, Higginbotham J, Akinremi T, Suther S, Soliman K: Microarray comparison of prostate tumor gene expression in African-American and Caucasian American males: a pilot project study. Infectious Agents and Cancer 2009, 4(Suppl 1):S3.

37. Wallace TA, Prueitt RL, Yi M, Howe TM, Gillespie JW, Yfantis HG, Stephens RM, Caporaso NE, Loffredo CA, Ambs S: Tumor Immunobiological Differences in Prostate Cancer between AfricanAmerican and European-American Men. Cancer Res 2008, 68(3):927-936.

38. Timofeeva OA, Zhang X, Ressom HW, Varghese RS, Kallakury BV, Wang K, Ji Y, Cheema A, Jung M, Brown ML, Rhim JS, Dritschilo A: Enhanced expression of SOS1 is detectable in prostate cancer epithelial cells from African-American men. Int J Oncol 2009, 35(4):751-60.

39. Gamazon ER, Zhang W, Konkashbaev A, Duan S, Kistner EO, Nicolae DL, Dolan ME, Cox NJ: SCAN: SNP and copy number annotation.
Bioinformatics 2010, 26(2):259-62, Epub 2009 Nov 17.PMID: 19933162 [PubMed - indexed for MEDLINE].

40. Nicolae DL, Gamazon E, Zhang W, Duan S, Dolan ME, Cox NJ: TraitAssociated SNPs Are More Likely to Be eQTLs: Annotation to Enhance Discovery from GWAS. PLoS Genet 2010, 6(4):e1000888, doi:10.1371/journal. pgen.1000888 PMID 20369019.

41. Gamazon ER, Zhang W, Konkashbaev A, Duan S, Kistner E, Nicolae DL, Dolan ME, Cox NJ: SCAN: SNP and copy number annotation. Bioinformatics, Advance Access published on November 17, 2009 doi:10.1093/bioinformatics/btp644 PMID 19933162.

42. Duan S, Huang RS, Zhang W, Bleibel WK, Roe CA, Clark TA, Chen TX, Schweitzer AC, Blume JE, Cox NJ, Dolan ME: Genetic Architecture of Transcript-Level Variation in Humans. Amer. J. Human Genetics 2008, 82:1101-1113, PMID 18439551.

43. Zhang W, Duan S, Kistner EO, Bleibel WK, Huang RS, Clark TA, Chen TX, Schweitzer AC, Blume JE, Cox NJ, Dolan ME: Evaluation of Genetic Variation Contributing to Differences in Gene Expression Between Populations. Amer. J. Human Genetics 2008, 82:631-640, PMID 18313023.

44. Duan S, Zhang W, Bleibel WK, Cox NJ, Dolan ME: SNPinProbe_1.0: A database for filtering out probes in the Affymetrix GeneChip(R) Human Exon 1.0 ST array potentially affected by SNPs. Bioinformation 2008, 2(10):469-70, PMID 18841244.

45. Theodore S, Sharp S, Zhou J, et al: Establishment and characterization of a pair of non-malignant and malignant tumor derived cell lines from an African American prostate cancer patient. International journal of oncology 37:1477-82.

46. Stone KR, Mickey DD, Wunderli H, Mickey GH, Paulson DF: Isolation of a human prostate carcinoma cell line (DU 145). International journal of cancer 1978, 21:274-81.

47. Dondi $\mathrm{D}$, et al: Growth-inhibitory effects of luteinizing hormone-releasing hormone (LHRH) agonists on xenografts of the DU 145 human androgen-independent prostate cancer cell line in nude mice. Int $J$ Cancer 1998, 76(4):506-11.

48. Jungwirth A, Pinski J, Galvan G, et al: Inhibition of growth of androgenindependent DU-145 prostate cancer in vivo by luteinising hormonereleasing hormone antagonist Cetrorelix and bombesin antagonists RC3940-II and RC-3950-II. Eur J Cancer 1997, 33:1141-8.

49. Turner $\mathrm{T}$, Chen $\mathrm{P}$, Goodly LJ, Wells A: EGF receptor signaling enhances in vivo invasiveness of DU-145 human prostate carcinoma cells. Clinical \& experimental metastasis 1996, 14:409-18.

50. Wells A, Welsh JB, Lazar CS, Wiley HS, Gill GN, Rosenfeld MG: Ligandinduced transformation by a noninternalizing epidermal growth factor receptor. Science 1990, 247:962-964

51. Xie H, Turner T, Wang MH, Singh RK, Siegal GP, Wells A: In Vitro invasiveness of DU-145 human prostate carcinoma cells is modulated by EGF receptor-mediated signals. Clin Exp Metastasis 1995, 13(6):407-19.

52. Horoszewicz JS, et al: The LNCaP cell line-a new model for studies on human prostatic carcinoma. Prog Clin Biol Res 1980, 37:115-32.

53. Tusher VG, Tibshirani $R$, Chu G: Significance analysis of micro arrays applied to the lonizing radiation response. Proc Nation Acad Sci USA 2001, 98(9):5116-21

54. Odedina FT, Akinremi TO, Chinegwundoh F, Roberts R, Yu D, Reams RR, Freedman ML, Rivers B, Green BL, Kumar N: Prostate cancer disparities in Black men of African descent: a comparative literature review of prostate cancer burden among Black men in the United States, Caribbean, United Kingdom, and West Africa. Infect Agent Cancer 2009, 10(4 Suppl 1):S2.

55. Liu Y, Peng $H$, Zhang JT: Expression profiling of $A B C$ transporters in a drug-resistant breast cancer cell line using AmpArray. Mol Pharmacol 2005, 68:430-8

56. Huss WJ, Gray DR, Greenberg NM, Mohler JL, Smith GJ: Breast cancer resistance protein-mediated efflux of androgen in putative benign and malignant prostate stem cells. Cancer research 2005, 65:6640-50.

57. Theodore SC, Rhim JS, Turner T, Yates C: MiRNA 26a expression in a novel panel of African American prostate cancer cell lines. Ethn Dis 20:51-96100

58. Peterziel H, Mink S, Schonert A, Becker M, Klocker H, Cato AC: Rapid signalling by androgen receptor in prostate cancer cells. Oncogene 1999, 18:6322-9.

59. Odero-Marah VA, Wang R, Chu G, et al: Receptor activator of NF-kappaB Ligand (RANKL) expression is associated with epithelial to mesenchymal transition in human prostate cancer cells. Cell Res 2008, 18:858-70. 
60. Shuch B, Mikhail M, Satagopan J, et al: Racial disparity of epidermal growth factor receptor expression in prostate cancer. J Clin Oncol 2004, 22:4725-9.

61. Gan Y, Shi C, Inge L, Hibner M, Balducci J, Huang Y: Differential roles of ERK and Akt pathways in regulation of EGFR-mediated signaling and motility in prostate cancer cells. Oncogene 29:4947-58.

62. Yates $C$, Wells $A$, Turner T: Luteinising hormone-releasing hormone analogue reverses the cell adhesion profile of EGFR overexpressing DU145 human prostate carcinoma subline. British journal of cancer 2005, 92:366.

63. Yates CC, Shepard CR, Stolz DB, Wells A: Co-culturing human prostate carcinoma cells with hepatocytes leads to increased expression of Ecadherin. British journal of cancer 2007, 96:1246-52.

doi:10.1186/1750-9378-6-S2-S1

Cite this article as: Reams et al:. Detecting gene-gene interactions in prostate disease in African American men. Infectious Agents and Cancer 2011 6(Suppl 2):S1.

\section{Submit your next manuscript to BioMed Central} and take full advantage of:

- Convenient online submission

- Thorough peer review

- No space constraints or color figure charges

- Immediate publication on acceptance

- Inclusion in PubMed, CAS, Scopus and Google Scholar

- Research which is freely available for redistribution

Submit your manuscript at www.biomedcentral.com/submit 